\title{
Influence of in Vitro Generation Temperature and Post-in Vitro Cold Storage Duration on Growth Response of Lilium longiflorum Bulblets
}

\author{
Wendy S. Higgins' and Dennis P. Stimart ${ }^{2}$ \\ Department of Horticulture, University of Maryland, College Park, MD 20742 \\ Additional index words. micropropagation, shoot emergence, anthesis
}

\begin{abstract}
Lilium longiflorum Thunb. 'Ace' bulblets generated in vitro at 25 or $30 \mathrm{C}$ were stored at $4 \mathrm{C}$ for $\mathrm{O}, 1,2,4$, or 6 weeks after removal from culture and before planting to ascertain the effects of in vitro generation temperature and post-in vitro cold storage duration on bulblet growth responses during 36 weeks of greenhouse growth. Increasing post-in vitro storage duration decreased the number of days to first leaf emergence and percentage of plants producing shoots within 36 weeks, but increased the number of days to shoot emergence and anthesis, leaf number, and flower bud number. The length of time required for bulblet development from planting to shoot emergence was affected by storage duration more than periods from shoot emergence to visible bud and anthesis. It is feasible to produce highquality $L$. longiflorum pot plants from in vitro-produced bulblets.
\end{abstract}

Lilium longiflorum is usually propagated by scaling. This technique yields bulblets that are grown in the field for 3 to 5 years and used for greenhouse forcing. Field-produced lily bulbs carry pathogenic organisms and pests that can manifest themselves during forcing. Development of technology to produce high-quality L. longiflorum pot plants from in vitro-derived bulblets would be useful.

Previous research with $L$. longiflorum showed that in vitro temperature affected bulblet morphology post-in vitro (Stimart and Ascher, $1981 \mathrm{~b}$ ). Bulblets generated in vitro at 30C produced leaves and had a more rapid rate of leaf emergence than those generated at 25C (Stimart and Ascher, 1981a). Chilling bulblets generated at either in vitro temperature for 1 or more weeks at $4 \mathrm{C}$ after their removal from tissue culture enhanced the number of bulblets producing leaves and increased the rate of leaf emergence (Stimart et al., 1982). First leaves produced by in vitrogenerated bulblets were scaly leaves (leaves attached to scales) (Stimart et al., 1983). Up to $50 \%$ of the bulblets generated at $30 \mathrm{C}$ produced an axis, a shoot with leaves attached, within 14 weeks of removal from tissue culture. However, none of the bulblets generated at $25 \mathrm{C}$ bolted within this time period.

Although previous research (Stinmrt and Ascher, 1978, 1981a, 1981b; Stimart et al., 1982, 1983) examined bulblet development up to 14 weeks post-in vitro, we found no investigations detailing growth in a greenhouse. Consequently, our study examined the effects of in vitro generation temperature and postin vitro cold storage duration on growth response of $L$. longiflorum bulblets in a greenhouse.

\section{Materials and Methods}

Lilium longiflorum 'Ace' bulbs, grown in Smith River Valley, Calif., were used as tissue culture explant sources. Precooled bulbs were received at the Univ. of Maryland, College

Received for publication 16 Nov. 1989. Scientific Article no. A-4450. Contribution no. 7441 of the Maryland Agricultural Experiment Station. The cost of publishing this paper was defrayed in part by the payment of page charges. Under postal regulations, this paper therefore must be hereby marked advertisement solely to indicate this fact.

'Graduate Research Assistant. Present address: U.S. National Arboretum, 3501 New York Avenue, N. E., Washington, DC 20002.

${ }^{2}$ Professor. Present address: University of Wisconsin, Dept. of Horticulture, 1575 Linden Dr., Madison, WI 53706.
Park ( $38^{\circ} 58^{\prime} \mathrm{N}$ latitude), in Dec. 1983 and stored at $4 \mathrm{C}$ for at least 4 months, until needed.

The procedure used for in vitro generation of bulblets was described previously (Stimart and Ascher, 1978). In conventional lily culture, small bulbs originating from scale propagation are referred to as bulblets for the 1st year of independent growth (De Hertogh et al., 1971). Likewise, in this study the term bulblet is used to refer to the bulb structure for the 1st year of growth following removal from tissue culture.

Bulblets were removed from culture after $14,16,18,19$, or 20 weeks and stored at $4 \mathrm{C}$ for $6,4,2$, 1, or O weeks, respectively, in moist, sterile vermiculite in plastic bags. On 17 Sept. 1984 , bulblets were removed from storage and individually potted 1 to $2 \mathrm{~cm}$ deep in $10-\mathrm{cm}$ square plastic pots $(450 \mathrm{ml})$ in a 1 peat : 1 vermiculite $(\mathrm{v} / \mathrm{v})$ growing medium. Before planting, fresh weight was measured for each bulblet and the number of scales was counted for 15 bulblets per treatment. Fifteen bulblets per treatment were planted for each of two harvest dates: 16 and 36 weeks after planting. Bulblets were grown in the greenhouse in a randomized complete-block design with 15 blocks. Sixteen-hour days were provided from planting to harvest by extending the natural day with incandescent lights placed 115 $\mathrm{cm}$ above the bench and spaced $180 \mathrm{~cm}$ apart, which provided $3.0 \mu \mathrm{mol} \cdot \mathrm{s}^{-1} \cdot \mathrm{m}^{-2}(400$ to $700 \mathrm{~nm})$ light, as measured by a light meter (LI-COR LI-185B, LI-COR, Lincoln, Neb.) at bench level. Minimum greenhouse temperature was $16.5 \mathrm{C}$, and automatic venting occurred at $24 \mathrm{C}$.

A fungicide drench (Banrot; Mallinckrodt, St. Louis) and 2.5 g 14N-6. 1P-11.6K Osmocote were applied to the growing medium surface of each pot at planting. Plants were fertilized with 20N-20P-20K to achieve 150 ppm N biweekly.

The number of days from planting until first leaf emergence, fresh weight of the shoot (the above-ground portion of the lily plant), number of leaves per plant, bulblet fresh weight, and number of scales per bulblet were recorded. Plants to be harvested at 36 weeks were transplanted to $15-\mathrm{cm}$ azalea pots (1400 ml) after 24 weeks. Additional data collected on these plants included: the number of days to shoot emergence, visible bud, and anthesis; plant height (measured from the soil line to the base of the lowest pedicel); number of stem bulblets; and number of flower buds. The number of days from first leaf emergence to shoot emergence, from shoot emergence to visible bud, and from visible bud to anthesis were calculated.

Analysis of variance with linear, quadratic, and cubic or- 
thogonal contrasts was performed on all data sets. Weighted least squares analysis was done to correct the variance heterogeneity of certain variables.

\section{Results}

Bulblet fresh weight and the number of scales per bulblet after removal from post-in vitro storage were significantly different due to in vitro generation temperature but not due to storage duration. Fresh weights averaged 0.21 and $0.18 \mathrm{~g}$ and number of scales per bulblet were 5.1 and 4.0 for bulblets generated at 25 and $30 \mathrm{C}$, respectively.

With increasing cold storage duration, days to first leaf emergence decreased for bulblets generated at either in vitro temperature. (Table 1). Bulblets receiving no cold storage and generated at $30 \mathrm{C}$ needed fewer days to unfold the first leaf than $25 \mathrm{C}$ bulblets. The number of days from first leaf emergence to shoot emergence increased with increasing cold storage. In contrast, increasing storage duration decreased the number of days from shoot emergence to visible bud. Bulblets generated at $25 \mathrm{C}$ required consistently more days for this phase of development than $30 \mathrm{C}$ bulblets. There was a small decrease in the number of days from visible bud to anthesis as storage duration increased. Overall, the number of days from planting until anthesis increased with increasing cold storage.

The percentage of bulblets eaching the different stages of development from planting to anthesis appeared to depend on in vitro generation temperature and post-in vitro storage duration (Table 1). Generally, a greater percentage of bulblets reached anthesis within 36 weeks' if derived at $25 \mathrm{C}$ than at $30 \mathrm{C}$. As storage duration increased, there was a substantial decrease in the percentage of plants attaining anthesis by 36 weeks.

Leaf number and shoot fresh weight 16 weeks after planting generally decreased as storage duration increased (Table 2). At 36 weeks, the trend had reversed. The number of scales per bulblet and bulblet fresh weight at 16 weeks generally increased as storage duration increased. At 36 weeks, no consistent trend was apparent. To avoid complications due to differential development, only plants with emerged shoots were included in the data in Table 2 for the 36-week harvest. Increasing cold storage generally resulted in increased flower bud number and plant height and decreased stem bulblet number (Table 3). Leaf number at 36 weeks (Table 2) correlated positively with days to shoot emergence (Table 1) $(\mathrm{r}=0.72), P=0.001)$, and the regression in Fig. 1 shows increasing leaf number resulted in increased flower bud number.

\section{Discussion}

Clearly, bulblet growth responses can be manipulated through in vitro generation temperature and post-in vitro cold storage duration. Analysis of plant growth phases from planting to first leaf emergence, first leaf emergence to shoot emergence, shoot emergence to visible bud, and visible bud to anthesis indicates greatest variability in growth responses occurred from planting to shoot emergence (Table 1). The number of days from shoot emergence to anthesis was more uniform, regardless of treatment, and fell within the approximate 120-day range that growers try to achieve when forcing conventionally produced L. longiflorum (Langhans and Weiler, 1967). Consequently, the period of growth from planting to shoot emergence should be a focal point for future experiments when trying to flower micropropagated bulblets.

The varying lengths of in vitro generation time (14 through 20 weeks) before post-in vitro cold storage (6 through $\mathrm{O}$ weeks) could have influenced bulblet growth. It should be kept in mind that bulblets from cultures started at the same time are not necessarily the same age. Although bulblet weight and the number of scales per bulblet were found to be different due to in vitro generation temperature before planting, there were no differences in bulblet weight among cold storage duration treatments. This result suggests that bulblets generated at the same in vitro

Table 1. Intervals (days) between planting and first leaf emergence, shoot emergence, visible bud, and anthesis of L. longiflorum in response to in vitro generation temperature and post-in vitro storage duration at $4 \mathrm{C}$.

\begin{tabular}{|c|c|c|c|c|c|c|}
\hline $\begin{array}{l}\text { In vitro } \\
\text { temp } \\
\left({ }^{\circ} \mathrm{C}\right)\end{array}$ & $\begin{array}{c}\text { Weeks } \\
\text { at } \\
4 \mathrm{C}\end{array}$ & $\begin{array}{l}\text { Planting to } \\
\text { first leaf } \\
\text { emergence }\end{array}$ & $\begin{array}{c}\text { First leaf } \\
\text { to shoot } \\
\text { emergence }\end{array}$ & $\begin{array}{c}\text { Shoot emergence } \\
\text { to visible bud }\end{array}$ & $\begin{array}{l}\text { Visible bud } \\
\text { to anthesis }\end{array}$ & $\begin{array}{c}\text { Planting to } \\
\text { anthesis }\end{array}$ \\
\hline & & & & Days $s^{\mathbf{y}}$ & & \\
\hline \multirow[t]{5}{*}{25} & 0 & $31(100)$ & $86(93)$ & $66(80)$ & $26(80)$ & $210(80)$ \\
\hline & 1 & $20(100)$ & $98(100)$ & $63(100)$ & $26(100)$ & $207(100)$ \\
\hline & 2 & $17(100)$ & $111(100)$ & $65(87)$ & $25(87)$ & $220(87)$ \\
\hline & 4 & $17(100)$ & $129(93)$ & $59(87)$ & $25(87)$ & $230(87)$ \\
\hline & 6 & $15(100)$ & $145(60)$ & $58(53)$ & $25(47)$ & $230(47)$ \\
\hline \multicolumn{7}{|l|}{ Significance } \\
\hline Linear & & $* *$ & $* *$ & $* *$ & $* *$ & $* *$ \\
\hline Quadratic & & $* *$ & NS & NS & NS & NS \\
\hline Cubic & & $* *$ & NS & NS & NS & NS \\
\hline \multirow[t]{5}{*}{30} & 0 & $23(100)$ & $79(100)$ & $56(53)$ & $30(53)$ & $190(53)$ \\
\hline & 1 & $18(100)$ & $92(93)$ & $54(67)$ & $28(67)$ & $193(67)$ \\
\hline & 2 & $17(100)$ & $144(73)$ & $52(53)$ & $25(53)$ & $232(53)$ \\
\hline & 4 & $16(100)$ & $177(67)$ & $47(47)$ & $23(20)$ & $239(20)$ \\
\hline & 6 & $15(100)$ & $167(53)$ & $43(47)$ & $23(27)$ & $233(27)$ \\
\hline \multicolumn{7}{|l|}{ Significance } \\
\hline Linear & & ** & ** & $* *$ & ** & $* *$ \\
\hline Quadratic & & $* *$ & $* *$ & NS & $* *$ & $* *$ \\
\hline
\end{tabular}

${ }^{2}$ Weighted least square analysis was done to correct for variance heterogeneity. ${ }^{y}$ Values in parentheses are the percentage of plants responding by 36 weeks. $\mathrm{ns}, *, * *$ Nonsignificant or significant at $P=0.0 .5$ or 0.01 , respectively. 
Table 2. Number of leaves and scales, and shoot and bulblet fresh weight of L. longiflorum 16 and 36 weeks after planting in response to in vitro generation temperature and post-in vitro storage duration at 4C.

\begin{tabular}{|c|c|c|c|c|c|c|c|c|c|}
\hline \multirow[b]{3}{*}{$\begin{array}{l}\text { In vitro } \\
\text { temp } \\
\left({ }^{\circ} \mathrm{C}\right) \\
\end{array}$} & \multirow{3}{*}{$\begin{array}{c}\text { Weeks } \\
\text { at } \\
4 \mathrm{C} \\
\end{array}$} & \multicolumn{8}{|c|}{ Time after planting } \\
\hline & & \multicolumn{4}{|c|}{16 weeks } & \multicolumn{4}{|c|}{36 weeks $^{2}$} \\
\hline & & $\begin{array}{c}\text { Leaves } \\
\text { (no.) }\end{array}$ & $\begin{array}{c}\text { Shoot } \\
\text { fresh } \\
\text { wt (g) }\end{array}$ & $\begin{array}{l}\text { Scales } \\
(\text { no. })^{y}\end{array}$ & $\begin{array}{c}\text { Bulblet } \\
\text { fresh } \\
\text { wt }(\mathrm{g})^{\mathrm{y}}\end{array}$ & $\begin{array}{l}\text { Leaves } \\
\text { (no.) }{ }^{y}\end{array}$ & $\begin{array}{c}\text { Shoot } \\
\text { fresh } \\
\text { wt }(g)^{y}\end{array}$ & $\begin{array}{c}\text { Scales } \\
\text { (no.) }\end{array}$ & $\begin{array}{c}\begin{array}{c}\text { Bulblet } \\
\text { fresh }\end{array} \\
\text { wt (g) }\end{array}$ \\
\hline \multirow[t]{5}{*}{25} & 0 & 10.1 & 4.0 & 4.8 & 0.5 & 37 & 33 & 46 & 31 \\
\hline & 1 & 11.6 & 5.4 & 7.0 & 0.9 & 48 & 39 & 51 & 33 \\
\hline & 2 & 12.1 & 6.2 & 8.2 & 1.3 & 54 & 51 & 52 & 30 \\
\hline & 4 & 8.4 & 3.4 & 11.1 & 1.1 & 64 & 57 & 55 & 28 . \\
\hline & 6 & 6.5 & 2.6 & 11.3 & 1.1 & 70 & 67 & 49 & 23 \\
\hline \multicolumn{10}{|l|}{ Significance } \\
\hline Linear & & $* *$ & ** & ** & $* *$ & $* *$ & $* *$ & NS & $*$ \\
\hline Quadratic & & $* *$ & $* *$ & $* *$ & $* *$ & NS & NS & NS & NS \\
\hline Cubic & & $*$ & $* *$ & NS & $* *$ & NS & NS & NS & NS \\
\hline \multirow[t]{5}{*}{30} & 0 & 14.9 & 7.5 & 3.6 & 0.6 & 28 & 23 & 45 & 36 \\
\hline & 1 & 12.5 & 6.8 & 8.0 & 1.1 & 37 & 27 & 62 & 54 \\
\hline & 2 & 9.7 & 4.8 & 14.5 & 1.6 & 75 & 62 & 56 & 32 \\
\hline & 4 & 7.7 & 3.5 & 12.8 & 1.4 & 73 & 68 & 45 & 18 \\
\hline & 6 & 7.9 & 3.6 & 13.7 & 1.4 & 73 & 64 & 51 & 22 \\
\hline \multicolumn{10}{|l|}{ Significance } \\
\hline Linear & & $* *$ & $* *$ & $* *$ & $* *$ & $* *$ & $* *$ & NS & $* *$ \\
\hline Quadratic & & $* *$ & $* *$ & $* *$ & $* *$ & $* *$ & $* *$ & NS & NS \\
\hline Cubic & & NS & NS & $* *$ & $* *$ & NS & NS & $* *$ & $* *$ \\
\hline
\end{tabular}

${ }^{2}$ Data sets composed of plants with emerged shoots only.

${ }^{y}$ Weighted least squares analysis was done to correct for variance heterogeneity.

NS,*,**Nonsignificant or significant at $P=0.05$ or 0.01 , respectively.

Table 3. Number of flower buds and stem bulblets per plant and plant height of L. longiforum in response to in vitro generation temperature and post-in vitro storage duration at $4 \mathrm{C}$.

\begin{tabular}{lcccc}
\hline \hline $\begin{array}{l}\text { In vitro } \\
\text { temp } \\
\left({ }^{\circ} \mathrm{C}\right)\end{array}$ & $\begin{array}{c}\text { Weeks } \\
\text { at } \\
4 \mathrm{C}\end{array}$ & $\begin{array}{c}\text { Flower } \\
\text { buds } \\
(\text { no. })^{\text {z.y }}\end{array}$ & $\begin{array}{c}\text { Stem } \\
\text { bulblets } \\
(\text { no. })^{2}\end{array}$ & $\begin{array}{c}\mathrm{Ht} \\
(\mathrm{cm})\end{array}$ \\
\hline $25^{-}$ & 0 & $0.9(100)$ & 8.1 & 35 \\
& 1 & $1.3(100)$ & 6.8 & 39 \\
& 2 & $2.0(93)$ & 5.2 & 42 \\
& 4 & $1.9(93)$ & 3.8 & 41 \\
Significance & 6 & $1.9(53)$ & 1.0 & 46 \\
$\quad$ Linear & & $* *$ & $* *$ & $* *$ \\
Quadratic & & $*$ & NS & NS \\
Cubic & & NS & NS & NS \\
30 & 0 & $0.5(100)$ & 6.9 & 30 \\
& 1 & $0.7(93)$ & 2.1 & 35 \\
& 2 & $2.6(73)$ & 0.6 & 47 \\
& 4 & $2.4(53)$ & 0.8 & 51 \\
Significance & 6 & $2.3(53)$ & 0.5 & 42 \\
$\quad$ Linear & & & & \\
Quadratic & & $* *$ & $* *$ & $* *$ \\
Cubic & & NS & $* *$ & Ns \\
\hline
\end{tabular}

${ }^{z}$ Weighted least squares analysis was done to correct for variance heterogeneity.

'Values in parentheses are the percentage of plants on which the num-

ber of flower buds could be determined by 36 weeks.

$\mathrm{NS}, *, * *$ Nonsignificant or significant at $P=0.05$ or 0.01 , respectively.

temperature were physically similar before planting, regardless of cold storage duration. However, bulblet growth response from equalization of in vitro generation time should be examined in the future.

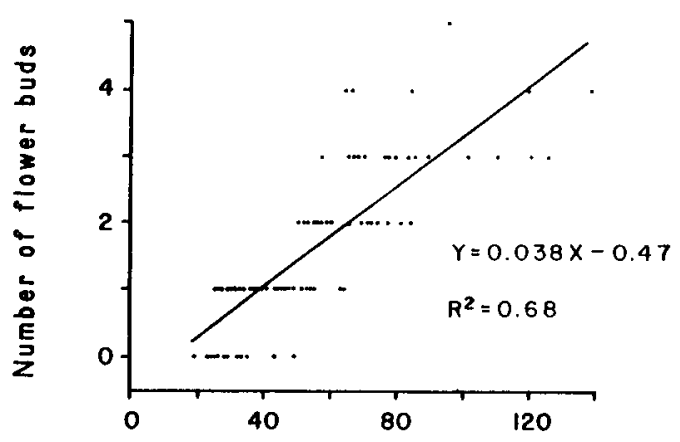

Number of leaves

Fig. 1. Relationships between number of leaves and number of flower buds per plant of L. longiflorum. Plants having blind shoots or aborted buds were counted as having $\mathrm{O}$ flower buds.

No axis elongation (shoot emergence) within 14 weeks of planting was reported previously from bulblets generated at $25 \mathrm{C}$ in contrast to $50 \%$ by those generated at 30C (Stimart et al., 1983). In our work, shoots did not start emerging from bulblets generated in vitro at $25 \mathrm{C}$ until $=16$ weeks after planting, indicating that previous research was of insufficient duration for $25 \mathrm{C}$ bulblets to bolt.

Cold storage of bulblets after removal from culture stimulated emergence of scaly leaves. It is evident that 1 week of cold storage resulted in a large decrease in days to first leaf emergence over no cold storage, and 2 or more weeks of cold storage resulted in only a small additional decrease (Table 1). Therefore, maximum benefit is achieved with 1 week of cold, since increasing cold storage adds days to forcing. The importance of rapid first leaf emergence becomes a moot point: although increasing cold storage increases the rate of first leaf emergence, 
bulblets receiving no cold have the fastest rate of shoot emergence. This result is in contrast to the response of conventionally propagated bulbs used for forcing, which have fastest shoot emergence with increasing cold storage duration (Weiler and Langhans, 1968a). Apparently, increasing cold storage of in vitro-generated bulblets delays either shoot formation or emergence.

Rapid shoot emergence of bulblets was associated with a high incidence of blind shoots and aborted flower buds (20\% to $40 \%$ for bulblets stored $\mathrm{O}$ to 1 weeks at $4 \mathrm{C}$; data not presented). Increasing cold storage duration delayed shoot emergence (Table 1), with a corresponding increase in leaf (Table 2) and flower bud (Table 3) number. These data suggest that a critical leaf number is essential to support floral development and high bud count.

Whether in vitro-generated bulblets require vernalization for floral initiation to occur is unknown. Cold storage of source bulbs before tissue culture may remove the necessity of vernalization. Post-in vitro cold storage should not be equated with the vernalizing cold storage conventional bulbs receive before forcing. If post-in vitro cold storage were a vernalizing treatment, bulblets receiving 6 weeks of storage would have produced flowers sooner than bulblets receiving no cold. Exactly the opposite occurred. If vernalization were required by bulblets, nighttime greenhouse temperatures $<21$. IC and extended daylengths could have fulfilled this requirement (Weiler and Langhans, 1968a, 1968b). Vernalizing temperatures may not have been perceived by bulblets until shoot formation had occurred. If increasing duration of $4 \mathrm{C}$ storage delayed shoot formation, this would explain why bulblets receiving no cold were vernalized and produced flowers sooner than other treatments.

Trends in bulblet fresh weight changed over the course of the experiment. The low weight at 16 weeks of bulblets given $\mathrm{O}$ or 1 week of cold storage indicates that bulblets that had rapid shoot emergence initially expended their metabolizes in that process, while other bulblets partitioned a greater portion of their metabolizes into bulblet growth. By 36 weeks, plants that had bolted rapidly had completed flowering and were partitioning metabolizes into bulblet "growth, whereas other plants were not expending their metabolizes in shoot development and flowering. This explanation is supported by research (Wang and Breen, 1983) that indicated floral development is a major metabolic sink in L. longiflorum; however, in the post-bloom stage
(5 weeks after anthesis) $80 \%$ of the translocated ${ }^{14} \mathrm{C}$ from the treated leaf was in the bulb.

Rapid shoot emergence and flowering are essential for economic production of L. longiflorum from in vitro-generated bulblets. However, increasing the rate of shoot emergence reduced leaf number and, consequently, flower bud number. Moderating the rate of shoot emergence through manipulation of in vitro generation temperature and post-in vitro storage conditions while optimizing plant nutrition, greenhouse temperatures, light intensity, and photoperiod could result in the production of high quality plants from in vitro-produced bulblets in a reasonable time.

\section{Literature Cited}

DeHertogh, A. A., A.N. Roberts, N.W. Stuart, R.W. Langhans, R.L. Linderman, R.H. Lawson, H.F. Wilkins, and D.C. Kiplinger. 1971. A guide to terminology for the Easter lily (Lilium-longiflorum Thunb.) HortScience 6:121-123.

Langhans, R. and T. Weiler. 1967. Factors affecting flowering, p. $37-$ 46. In: D.C. Kiplinger and R.W. Langhans (eds.). Easter lilies: the culture, diseases, insects, and economics of Easter lilies. Cornell Univ., Ithaca, N.Y.

Stimart, D.P. and P.D. Ascher. 1978. Tissue culture of bulb scale sections for asexual propagation of Lilium longiflorum Thunb. J. Amer. Soc. Hort. Sci. 103:182-184.

Stimart, D.P. and P.D. Ascher. 1981a. Foliar emergence from bulblets of Lilium longiflorum Thunb. as related to in vitro generation. J. Amer. Soc. Hort. Sci. 106:446-450.

Stimart, D.P. and P.D. Ascher, 1981b. Developmental responses of Lilium longiflorum bulblets to constant or alternating temperatures in vitro. J. Amer. Soc. Hort. Sci. 106:450-454.

Stimart, D. P., P.D. Ascher, and H.F. Wilkins. 1982. Overcoming dormancy in Lilium longiflorum bulblets produced in tissue culture. J. Amer. Soc. Hort. Sci. 107:1004-1007.

Stimart, D. P., P.D. Ascher, and H.F. Wilkins. 1983. Axis elongation from tissue-culture-generated bulblets of Lilium longiflorum Thunb. J. Amer. Soc. Hort. Sci. 108:99-101.

Wang, Y.T. and P.J. Breen. 1983. Flower removal alters the distribution of current photosynthates in Easter lily, Lilium longiflorum Thunb. HortScience 18:609. (Abstr.)

Weiler, T.C. and R.W. Langhans. 1968a. Determination of vernalization requirement of Lilium longiflorum (Thunb. ) cv. 'Ace'. Proc. Amer. Soc. Hort. Sci. 93:623-625.

Weiler, T.C, and R.W. Langhans. 1968b. Effect of photoperiod on vernalization requirement of Lilium longiflorum (Thunb. ) 'Ace'. Proc. Amer. Soc. Hort. Sci. 93:630-634. 